\title{
Contact allergens in registered cleaning agents for industrial and household use
}

\author{
Mari-Ann Flyvholm
}

\begin{abstract}
Cleaning work is a common cause of both irritant and allergic contact dermatitis. Cleaning agents for industrial and household use are registered in the Danish Product Register Data Base (PROBAS) according to a special notification rule issued by the Danish Environmental Protection Agency. About 2350 registered washing and cleaning agents containing about 1250 different chemical substances were marketed in Denmark in February 1992. The occurrence of 49 contact allergens in 16 different product types within washing and cleaning agents were listed. Preservatives and surface active agents made up the main part of contact allergens. Isothiazolinones and formaldehyde releasers were the most commonly registered preservatives, and coconut diethanolamide the most commonly registered surface active agent. The major product types registered as containing contact allergens were general cleaners, skin cleaners, hair shampoos, and floor polishes.
\end{abstract}

(British Fournal of Industrial Medicine 1993;50:1043-1050)

Several investigations have shown that cleaning personnel often have hand eczema. In a Finnish study on hospital workers performing wet work the prevalence was $44 \%$; most cases were caused by irritative contact dermatitis $(44 \%)$, then allergic contact dermatitis $(17 \%)$, combined allergic and irritative contact dermatitis (13\%), and atopic dermatitis (15\%). ${ }^{1}$ Those most commonly suffering from hand dermatitis were cleaners $(10 \%$ at the time of study). ${ }^{2}$ In a new Danish study based on 1237 cleaners $12 \%$ reported current skin symptoms and $30 \%$ skin symptoms several times each month. ${ }^{3}$ Cleaning work is a common cause of con-

\begin{tabular}{l}
\hline $\begin{array}{l}\text { National Institute of Occupational Health, } \\
\text { Copenhagen, Denmark } \\
\text { M-A Flyvholm }\end{array}$ \\
\hline
\end{tabular}

tact dermatitis due to the wet work and exposure to cleaning agents.

The most common category for products registered in the Danish Product Register Data Base (PROBAS) was cleaning agents. ${ }^{4}$ In February 1992 a total of about 5500 cleaning agents were registered in PROBAS corresponding to $13.5 \%$ of the total number of products registered with information on product category. In an earlier study on the occurrence of contact allergens in registered chemical products cleaning agents and toiletries made up the most common product categories and about half of the investigated allergens were found in cleaning agents. ${ }^{5}$

Based on a registration of washing and cleaning agents manufactured in or imported to Denmark in $1986^{6}$ a considerable number of cleaning agents used in Denmark are registered in PROBAS.

The purpose of the present study was to investigate the occurrence of contact allergens in cleaning agents as disclosed to and registered in PROBAS.

\section{Materials and methods}

DATA FROM PROBAS

This study is based on washing and cleaning agents, defined as products for washing and cleaning purposes that contain surface active agents. These products were notified to the Product Register Department according to a special order from the Danish Environmental Protection Agency and registered in PROBAS with information on product composition, function of each component, chemical and physical properties, volume manufactured or imported etc. ${ }^{6}$

The data included in the search consisted of all substances registered in the products either directly as a component or from raw materials. Obsolete components and products that according to PROBAS no longer exist on the Danish market in February 1992 were excluded.

\section{IDENTIFICATION OF CONTACT ALLERGENS}

Chemical Abstract Service Registry Numbers (CAS RN) for all components in the registered washing and cleaning agents were listed and used in a comparison by CAS RN for contact allergens 
identified from the following lists and verified by searches of publications for each substance: the European Standard Patch Test series from January $1989^{7}$; recommended patch test concentrations for preservatives, biocides, and antimicrobials; ; substances classified as contact allergens ("may cause sensitisation by skin contact", risk phrase R43) in official lists of dangerous substances in Denmark ${ }^{9}$ and in the other Scandinavian countries ${ }^{10-12}$; a Danish and a Canadian list of contact allergens ${ }^{13-14}$; contact allergens identified in earlier investigations, ${ }^{5}$ and in an unpublished study on contact allergens in detergents for textile washing.

\section{Results}

The degree of knowledge on product composition for the registered washing and cleaning agents was higher compared with the total product population in PROBAS. The complete product composition was known for $89 \%$ of the washing and cleaning agents and for $63 \%$ of the total product population.

A total of 2567 washing and cleaning agents from 121 companies were registered. The products were divided into 81 product types, of which 60 were registered with three or more products each. The most commonly registered product types were detergents for textile washing (262 products), degreasing agents (188 products), and general cleaners (186 products), disinfectants (136 products), machine dishwashing agents (119 products), high pressure cleaning agents (112 products), and dishwashing liquids (107 products). Based on volume manufactured or imported the most common product type was still detergents for textile washing $(29 \%)$, and the second was fabric softeners $(9 \%)$. Personal care products made up $546(21 \%)$ of the registered products. Details on the notifications and general information on the product population will be reported elsewhere (Hansen and Børglum, personal communication).

About 200 of the 2567 products registered from the notifications were no longer marketed in February 1992 according to information in PROBAS. These products and obsolete components in the registered products were not included in the search.

The remaining 2350 products contained a total of about 1250 different chemical substances identified by CAS RN. About 190 of the substances were contact allergens according to the lists mentioned earlier. Some widely distributed substances that according to clinical experiences seldom cause contact sensitisation were excluded-for example, EDTA and di and tetrasodium salts of EDTA. Besides these substances no evaluation of sensitising properties for the substances were made. About 120 of the contact allergens were registered in three or more washing and cleaning agents. These occurred in a total of about 40 different product types. The table shows only substances registered in two or more product types and the 16 product types registered with at least four of these substances.

Information on the technical function of each component in the products was included in the notifications. The table shows 49 allergens divided into groups based on the registered function and includes CAS RN, chemical names, references to lists of allergens, and the number of products registered for each substance divided into 16 different product types.

The number of products registered for each of the 49 allergens varied from five to 335 with a mean of 61 (median 25) divided into:

Eleven allergens registered in more than 100 products of which five were surface active agents (coconut diethanolamide, 2-propanol, polyethylene glycol mono(nonylphenyl) ether, propylene glycol, and cellulosecarboxymethylether sodium salt); four were preservatives (chloromethyl and methylisothiazolinone (5-chloro-2-methyl-4-isothiazolin-3-one and 2-methyl-4-isothiazolin-3-one), bromonitropropanediol, and formaldehyde); one was a colouring agent (tartrazine), and one was a corrosion inhibitor (triethanolamine).

Five allergens registered in 50-99 products of which three were preservatives (bromonitrodioxane and two parabens); one was a disinfectant and bleach (sodium hypochlorite), and one was an antioxidant (butylated hydroxytoluene).

Fourteen allergens registered in $20-49$ products of which seven were preservatives or disinfectants (benzalkonium chloride, 1,2-benzisothiazolin-3-one, sodium pyrosulphite, phenyl glycol, two parabens, and trichlorhydroxydiphenyl ether); two were surface active agents (stearic acid and tall oil fatty acid); two were fragrances (pine oil and citronella oil); one was a corrosion inhibitor (butyndiol); one $\mathrm{pH}$ regulating agent (acetic acid), and dodecylbenzene registered as impurities.

Ten allergens were registered in 10-19 products and nine allergens registered in less than 10 products.

Preservatives made up about half of the 40 allergens registered in more than 10 products, and nine were surface active agents. The rest consisted of fragrances, corrosion inhibitors, colours, and miscellaneous substances.

The most often registered product types containing contact allergens were general cleaners, skin cleaners, hair shampoos, and floor polishes.

THE MAIN PRODUCT TYPES REGISTERED WITH CONTENT OF EACH ALLERGEN

The main types of product registered with content 
of each allergen with the most often registered product types mentioned first were-

\section{Preservatives, disinfectants and antioxidants}

Twenty one of the allergens identified were registered as preservatives, disinfectants, or antioxidants. Chloromethyl and methylisothiazolinone were the most often registered; then bromonitropropanediol and formaldehyde, all registered in more than 100 products. The most often registered product types were hair shampoos, skin cleaners, and general cleaners.

Fifteen of the registered preservatives were found in skin cleaners and hair shampoos, and benzyl alcohol, 4 parabens, chloroallylhexaminium chloride, DMDM hydantoin (dimethyloldimethyl hydantoin), phenyl glycol, and trichlorhydroxydiphenyl ether were only registered in these product types. Benzalkonium chloride was mainly registered in disinfectants, and descaling agents. 1,2-Benzisothiazolin-3-one was registered in floor polishes and general cleaners. Bromonitrodioxane was registered in skin cleaners, hair shampoos, and general cleaners. Bromonitropropanediol was registered in dishwashing liquids, hair shampoos, and general cleaners. Butylated hydroxytoluene was mainly registered in skin cleaners, and hair shampoos. $p$-Chloro- $m$-cresol, which was found in a few products, was registered in general cleaners, and floor polishes. Chloromethyland methylisothiazolinone were registered in hair shampoos, skin cleaners, and general cleaners. Formaldehyde was registered in hair shampoos, general cleaners, dishwashing liquids, and skin cleaners. Paraformaldehyde, which was found in a few products, was registered in descaling agents, disinfectants, and toilet cleaners. Sodium hypochlorite was registered as the main component in disinfectants and general cleaners. Sodium pyrosulphite was only registered in floor polishes and general cleaners.

\section{Surface active agents}

Nine of the identified allergens were registered as surface active agents, emulsifiers, viscosity modifying agents, netting agents etc; three of these substances were registered in more than 200 products. The most often registered substance, coconut diethanolamide, was found in 335 products. Skin cleaners, general cleaners, degreasing agents, and detergents for textile washing were the most often registered product types. Cellulosecarboxymethylether sodium salt was registered in detergents for textile washing. Coconut diethanolamide was registered in hair shampoos, general cleaners, and skin cleaners. Polyethylene glycol mono(4-nonylphenyl) monoether, which was found in a few products, was registered in degreasing agents and dishwashing liquids. Polyethylene glycol mono(nonylphenyl) ether was mainly registered in general cleaners and degreasing agents. Polyoxyethylene sorbitan monooleate, which was found in a few products, was registered in hair shampoos and skin cleaners. Stearic acid was registered in skin cleaners, detergents for textile washing, and hair shampoos. Tall oil fatty acid was registered in degreasing agents and general cleaners. 2-Propanol was mainly registered in general cleaners, fabric softeners, descaling agents, and degreasing agents. Propylene glycol was mainly registered in hair shampoos, general cleaners, skin cleaners, and floor polishes.

\section{Fragrances}

Five fragrances were among the allergens that were registered in three or more products. The most often registered was pine oil, then citronella oil and eucalyptus oil. Most of these fragrances were registered in general cleaners.

\section{Corrosion inhibitors}

Four of the identified allergens were corrosion inhibitors. With the exception of triethanolamine registered in more than 100 products these substances were only found in a few products. Triethanolamine was mainly registered in general cleaners, degreasing agents, and high pressure cleaning agents. Butyndiol, N,N'-dibutylthiourea, and $\mathrm{N}, \mathrm{N}$ '-diethylthiourea were mainly registered in descaling agents.

\section{Colouring agents}

Only three allergenic colouring agents were registered in three or more products. Tartrazine (CI food yellow 4) was commonly registered, the other two were found in less than 10 products. CI acid yellow 3, tartrazine, and CI pigment food yellow 3 were registered in skin cleaners and hair shampoos; tartrazine was also registered in general cleaners, and dishwashing liquids.

\section{Miscellaneous substances}

The miscellaneous substances group consists of substances with functions such as softeners, solvents, $\mathrm{pH}$ regulating agents, residual monomers, and substances occurring as impurities. These substances were mainly registered in general cleaners and floor polishes, except for acetic acid, which was registered in disinfectants and descaling agents.

\section{THE MAIN ALLERGENS REGISTERED IN EACH}

PRODUCT TYPE

The main allergens registered in each product type with the most often registered substances mentioned first were-

\section{Automotive cleaners}

The allergens included the surface active agents polyethylene glycol mono(nonylphenyl) ether; the 
Contact allergens in registered cleaning agents. ${ }^{\star}$ Based on about 2350 notified washing and cleaning agents marketed in Denmark in February $\underset{\$}{\bar{\Phi}}$ 1992 and registered in PROBAS with information on product composition. The substances are grouped according to their technical function in ?. the products.

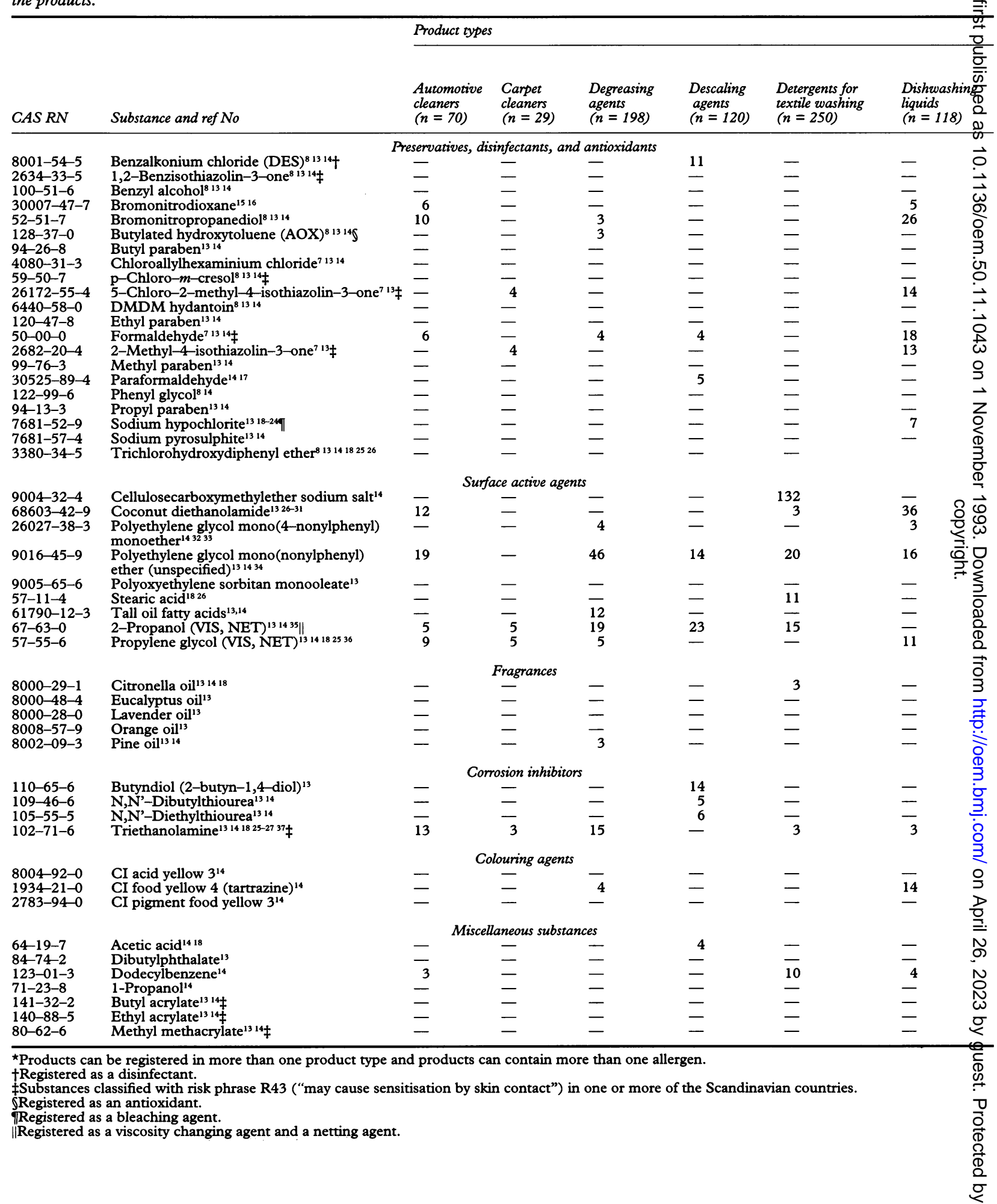




\begin{tabular}{|c|c|c|c|c|c|c|c|c|c|c|}
\hline $\begin{array}{l}\text { Disinfectants } \\
(n=132)\end{array}$ & $\begin{array}{l}\text { Fabric } \\
\text { softeners } \\
(n=67)\end{array}$ & $\begin{array}{l}\text { Floor } \\
\text { polishes } \\
(n=(94)\end{array}$ & $\begin{array}{l}\text { Foam } \\
\text { cleaning } \\
\text { agents } \\
(n=31)\end{array}$ & $\begin{array}{l}\text { Gen } \\
\text { clea } \\
(n=\end{array}$ & $\begin{array}{l}\text { Hair } \\
\text { shampoos } \\
(n=200)\end{array}$ & $\begin{array}{l}\text { High } \\
\text { pressure } \\
\text { cleaning } \\
\text { agents } \\
(n=115)\end{array}$ & $\begin{array}{l}\text { Skin } \\
\text { cleaners } \\
(n=224)\end{array}$ & $\begin{array}{l}\text { Sprinkler } \\
\text { liquids } \\
(n=29)\end{array}$ & $\begin{array}{l}\text { Toilet } \\
\text { cleaners } \\
\text { (generall } \\
\text { bowls) } \\
(n=74 / 62)\end{array}$ & $\begin{array}{l}\text { Total } \\
\text { products } \\
\text { for } \\
\text { substances } \\
(n=2347)\end{array}$ \\
\hline \multicolumn{11}{|c|}{ Preservatives, disinfectants, and antioxidants } \\
\hline 18 & - & - & - & 7 & - & 3 & - & - & $4 / 5$ & 43 \\
\hline- & 7 & 29 & - & 18 & - & - & - & - & - & 43 \\
\hline- & - & - & - & - & 5 & - & 4 & - & - & 9 \\
\hline - & - & 5 & - & 15 & 26 & - & 21 & - & - & 79 \\
\hline - & 4 & - & 3 & 22 & 25 & 4 & 15 & - & $4 / 3$ & 117 \\
\hline - & - & - & - & - & 11 & - & 28 & - & - & 52 \\
\hline - & - & - & - & - & 13 & - & 6 & - & - & 25 \\
\hline - & - & - & - & - & 4 & - & 8 & - & - & 17 \\
\hline - & - & 3 & - & 3 & - & - & - & - & - & 5 \\
\hline - & 9 & 13 & - & 34 & 54 & - & 40 & 3 & - & 171 \\
\hline - & - & - & - & - & 6 & - & 4 & - & - & 10 \\
\hline - & - & - & - & - & 11 & - & 6 & - & - & 23 \\
\hline - & - & 6 & - & 26 & 28 & 4 & 12 & - & -15 & 111 \\
\hline - & 8 & 11 & - & 31 & 54 & - & 40 & 3 & - & 166 \\
\hline - & - & - & - & - & 31 & - & 18 & - & - & 76 \\
\hline 4 & - & - & - & - & - & - & - & - & $-/ 4$ & 9 \\
\hline- & - & - & - & - & 11 & - & 5 & - & - & 25 \\
\hline- & - & - & - & - & 24 & - & 12 & - & - & 57 \\
\hline 44 & - & - & 4 & 17 & - & 3 & - & - & - & 87 \\
\hline- & - & 26 & - & 15 & - & - & - & - & - & 28 \\
\hline- & - & - & - & - & 4 & - & 15 & - & - & 22 \\
\hline \multicolumn{11}{|c|}{ Surface active agents } \\
\hline 3 & - & - & - & 3 & - & - & - & - & - & 150 \\
\hline - & - & 11 & - & 83 & 127 & 9 & 75 & - & $3 /-$ & 335 \\
\hline- & - & - & - & - & - & - & - & - & - & 13 \\
\hline 12 & - & 10 & - & 52 & - & 19 & 13 & - & $7 / 6$ & 222 \\
\hline- & - & - & - & - & 5 & - & 3 & - & - & 7 \\
\hline- & - & - & - & - & 7 & - & 11 & - & - & 42 \\
\hline - & - & - & - & 12 & - & - & 3 & - & - & 34 \\
\hline 10 & 34 & 4 & - & 56 & - & 9 & 3 & 8 & $15 / 10$ & 264 \\
\hline- & 7 & 31 & - & 42 & 43 & 5 & 34 & - & $3 /-$ & 199 \\
\hline \multicolumn{11}{|c|}{ Fragrances } \\
\hline- & - & - & - & 13 & - & - & 4 & - & - & 22 \\
\hline 4 & - & - & - & 8 & - & - & - & - & $4 / 3$ & 19 \\
\hline- & - & - & - & 6 & - & 4 & - & - & - & 14 \\
\hline - & - & - & - & 3 & - & - & 5 & - & - & 8 \\
\hline- & - & 4 & - & 26 & - & - & - & - & - & 39 \\
\hline \multicolumn{11}{|c|}{ Corrosion inhibitors } \\
\hline- & - & - & - & - & - & - & - & - & $3 / 6$ & 25 \\
\hline 3 & - & - & - & - & - & - & - & - & -13 & 9 \\
\hline- & - & - & 3 & 5 & - & - & - & - & - & 11 \\
\hline- & - & 6 & 4 & 33 & - & 15 & 10 & 4 & $3 /-$ & 114 \\
\hline \multicolumn{11}{|c|}{ Colouring agents } \\
\hline- & - & - & - & - & 3 & - & 4 & - & - & 9 \\
\hline- & - & 3 & - & 31 & 71 & - & 29 & - & $3 /-$ & 159 \\
\hline- & - & - & - & - & 6 & - & 3 & - & - & 9 \\
\hline \multicolumn{11}{|c|}{ Miscellaneous substances } \\
\hline 6 & - & - & - & - & - & - & - & - & - & 27 \\
\hline- & - & 12 & - & 4 & - & - & - & - & - & 13 \\
\hline - & - & 3 & - & 11 & - & 6 & 3 & - & - & 43 \\
\hline - & - & 18 & - & 9 & - & - & - & - & - & 19 \\
\hline- & - & 9 & - & 5 & - & - & - & - & - & 10 \\
\hline- & - & 7 & - & 5 & - & - & - & - & - & 7 \\
\hline- & - & 11 & - & 6 & - & - & - & - & - & 12 \\
\hline
\end{tabular}


corrosion inhibitor triethanolamine; and for preservatives the two formaldehyde releasers bromonitropropanediol and bromonitrodioxane and formaldehyde.

\section{Carpet cleaners}

Only 29 products were registered, and very few products for each substance.

\section{Degreasing agents}

The allergens were mainly surface active agents, with polyethylene glycol mono(nonylphenyl) ether as the most common substance then 2-propanol, and the corrosion inhibitor triethanolamine.

\section{Descaling agents}

The allergens included surface active agents such as 2-propanol, and polyethylene glycol mono(nonylphenyl) ether and the corrosion inhibitor butyndiol.

\section{Detergents for textile washing}

The allergens included mostly the surface active agent cellulosecarboxymethylether sodium salt and a few products with the corrosion inhibitor triethanolamine.

\section{Dishwashing liquids}

The allergens included the surface active agent coconut diethanolamide; the preservatives formaldehyde, the formaldehyde releaser bromonitropropanediol, and chloromethyl and methylisothiazolinone, and the colouring agent tartrazine.

\section{Disinfectants}

The allergens included sodium hypochlorite and benzalkonium chloride occurring as main components and the surface active agents polyethylene glycol mono(nonylphenyl) ether and 2-propanol.

\section{Fabric softeners}

Fabric softeners included the surface active agent 2-propanol and the isothiazolinone preservatives.

\section{Floor polishes}

Floor polishes included the surface active agent propylene glycol, preservatives 1,2-benzisothiazol3-one, and sodium pyrosulphite, from miscellaneous substances a solvent 1-propanol, a softener dibutylphthalate, and acrylates occurring as residual monomers. This group included general cleaners containing wax.

Foam cleaning agents

Only 31 products were registered, and very few products for each substance.

General cleaners

General cleaners included surface active agents coconut diethanolamide, 2-propanol, and polyethylene glycol mono(nonylphenyl) ether; preservatives mainly isothiazolinones, formaldehyde, and bromonitropropanediol; the corrosion inhibitor triethanolamine; and the colouring agent tartrazine.

\section{Hair shampoos}

Hair shampoos contained the surface active agents coconut diethanolamide and propylene glycol; preservatives chloromethyl and methylisothiazolinone, formaldehyde, formaldehyde releasers, and parabens and the colouring agent tartrazine.

\section{High pressure cleaning agents}

Mainly polyethylene glycol mono(nonylphenyl) ether and other surface active agents; the corrosion inhibitor triethanolamine.

\section{Skin cleaners}

Skin cleaners included surface active agents coconut diethanolamide and propylene glycol; preservatives, mainly chloromethyl and methylisothiazolinone; the antioxidant butylated hydroxytoluene; and the formaldehyde releasers bromonitrodioxane and methyl and propyl paraben; the colouring agent tartrazine.

\section{Sprinkler liquids}

Sprinkler liquids included the surface active agent 2 -propanol only registered in 29 products.

\section{Toilet cleaners (general and bowl)}

Only a few products were registered with each substance except for the surface active agent 2propanol.

\section{Discussion}

The data quality for the registered washing and cleaning agents was considerably higher than for the total product population registered in PROBAS. The degree of coverage for cleaning agents used in Denmark was estimated to be $95 \%$ in 1991 according to a survey on the use of cleaning agents in Danish institutions. ${ }^{38}$

As expected from earlier investigations the main allergens registered in washing and cleaning agents were preservatives. The other main group of substances was surface active agents. The most often registered preservatives were chloromethyl and methylisothiazolinone and the formaldehyde releaser bromonitropropanediol, all registered in more than 100 products. Surface active agents were registered in the largest number of products for each substance with five of the nine substances registered in more than 100 products; three of the five were registered in more than 200 products. Coconut diethanolamide was the most commonly registered substance, then 2-propanol and polyethylene 
glycol mono(nonylphenyl) ether. Only few fragrances were registered, probably because this information was not part of the compulsory information for the notifications. About half of the washing and cleaning agents were registered with unspecified perfumes in the contents. For corrosion inhibitors triethanolamine was the most commonly registered substance. For colouring agents tartrazine was the only substance registered in several products. For the group miscellaneous substances the most commonly registered substances were acrylic monomers and dodecylbenzene, the last occurring as an impurity.

Product types as general cleaners, skin cleaners, hair shampoos, and floor polishes were registered with content of many different allergens. The two product types (skin cleaners and hair shampoos) used for personal care involve direct skin contact, although with a short exposure time as they are both "wash off" products.

In this investigation nine substances classified as contact allergens (R43) in official lists of dangerous substances in one or more of the Scandinavian countries $^{9-12}$ were registered in three or more products among the notified washing and cleaning agents.

In an earlier study 19 out of 43 selected contact allergens were registered in cleaning agents. ${ }^{5}$ Twelve of these were included in the present study, five were registered in less than three products (benzoic acid, ethylenediamine, lauroyl diethanolamide, glutaraldehyde, and sodium borate), and two did not occur (colophony and cresol). The fact that glutaraldehyde was registered in 21 cleaning agents (mainly disinfectants) in the general product population in PROBAS and in less than three products in the registered washing and cleaning agents could indicate that the use of this strong allergen is decreasing.

Although cleaning work is often recognised as a cause of irritative contact dermatitis this study has shown that many contact allergens were registered in cleaning agents, which might contribute to the development and chronic nature of contact dermatitis among cleaners. Furthermore the occurrence of the same contact allergens in products for both industrial and household use could be an aggravating factor causing problems in treatment and prevention of occupational allergic contact dermatitis. Complete ingredient labelling for both industrial and household products would be the optimal way to provide information on occurrence of contact allergens in cleaning agents as the $1 \%$ limit for labelling contact allergens in chemical products, in many cases, is far above the concentration causing contact allergy.

I acknowledge all staff members at the Product Register Department at the National Institute of Occupational Health, Denmark involved in handling and engaged in improving the data quality for the many cleaning agents notified.

Requests for reprints to: Mari-Ann Flyvholm, National Institute of Occupational Health, Lersø Parkallé 105, DK-2100 Copenhagen, Denmark.

1 Lammintausta K. Risk factors for hand dermatitis in wet work. Atopy and contact sensitivity in hospital workers. Turku: University of Turku, 1982:1-65.

2 Lammintausta $\mathrm{K}$. Hand dermatitis in different hospital workers, who perform wet work. Dermatosen 1983:31:14-9.

3 Nielsen J, Bach E. Work environment and health among Danish cleaners. Copenhagen: The Danish Working Environment Fund, 1993 (in press). (In Danish)

4 Flyvholm M, Andersen P, Beck ID, Brandorff NP. PROBAS: The Danish Product Register Data Base-a national register of chemical substances and products. Fournal of Hazardous Matter 1992;30:59-69.

5 Flyvholm M. Contact allergens in registered chemical products. Contact Dermatitis 1991;25:49-56.

6 Danish Environmental Protection Agency. Order No 726 of 13 November 1987 on registration of washing and cleaning agents. Copenhagen: Danish Environmental Protection Agency, 1987.

7 Notice. Revised European standard series from 1 January 1989. Contact Dermatitis 1988;19:391.

8 Andersen KE, Rycroft RJG. Recommended patch test concentrations for preservatives, biocides and antimicrobials. Contact Dermatitis 1991;25:1-18.

9 Danish Environmental Protection Agency. Order No 805 of 15 December 1989. List of dangerous substances. Copenhagen: Danish Environmental Protection Agency, 1989.

10 Statens Forurensningstilsyn. List of dangerous substances, 19 fanuary 1983; changes 29 April 1986. Oslo: Statens Forurensningstilsyn, 1986.

11 Kemikalieinspektionen. List of allergenic substances, 1 fuly 1986; changes from February 1990. Stockholm: Kemikalieinspektionen, 1990.

12 Social- och hälsovårdsministeriet. Order on classification and labelling of dangerous substances. Helsingfors: Social- och hälsovărdsministeriet, 1988

13 Thomsen KG. Allergens in the working environment (in Danish: summary in English). AMI-report No 33/1990. Copenhagen: National Institute of Occupational Health, 1990.

14 Bouliane M, Baril M, Lapointe G. Sensibilisants cutanés et pulmonaires. Quebec: Commission de la santé et de la sécurité du travail, 1990 
15 Cosmetic Ingredient Review. Final report on the safety assessment of 5-Bromo-5-Nitro-1,3,-Dioxane. fournal of the American College of Toxicology 1990;9:279-88.

16 Potokar J, Greb W, Ippen H, Maibach HI, Schulz KH, Lorenz $\mathrm{P}$, Gloxhuber $\mathrm{C}$. Bronidox, a new preserving agent for cosmetics: properties and toxicological-dermatological assays. Fette Seife Anstrichm 1976:78:269-76.

17 Adams RM, Fisher AA. Contact allergen alternatives: 1986. f Am Acad Dermatol 1986;14:951-69.

18 Fisher AA. Contact dermatitis. 3rd ed. Philadelphia: Lea and Febiger, 1986.

19 Osmundsen PE. Contact dermatitis due to sodium hypochlorite. Contact Dermatitis 1978;4:177-8.

20 Eun HC, Lee AY, Lee YS. Sodium hypochlorite dermatitis. Contact Dermatitis 1984;11:45.

21 Habets JMW, Geursen-Reitsma AM, Stolz E, Van Joost T Sensitization to sodium hypochlorite causing hand dermatitis. Contact Dermatitis 1986;15:140-2.

22 Van Joost T, Habets JMW, Stolz E, Geursen-Reitsma AM Sodium hypochlorite sensitization. Contact Dermatitis 1987;16:114.

23 Hostynek J, Patrick E, Younger B, Maibach HI. Hypochlorite sensitivity in man. Contact Dermatitis 1989;20:32-7.

$24 \mathrm{Ng} \mathrm{SK}$, Goh CL. Contact allergy to sodium hypochlorite in Eusol. Contact Dermatitis 1989;21:281.

25 Cronin E. Contact dermatitis. Edinburgh: Churchill Livingstone, 1980.

26 De Groot AC. Adverse reactions to cosmetics. Groningen: State of University of Groningen, 1988.

27 Nater JP, De Groot AC. Unwanted effects of cosmetics and drugs used in dermatology. 2nd ed. Amsterdam: Elsevier, 1985.
28 Nurse DS. Sensitivity to coconut diethanolamide. Contact Dermatitis 1980;6:502.

29 De Groot AC, De Wit FS, Bos JD, Weyland JW. Contact allergy to cocamide DEA and lauramide DEA in shampoos. Contact Dermatitis 1987;16:117-8.

30 Hindson C, Lawlor F. Coconut diethanolamide in a hydraulic mining oil. Contact Dermatitis 1983;9:168.

31 De Boer EM, Van Ketel WG, Bruynzeel DP. Dermatoses in metal workers (II). Allergic contact dermatitis. Contact Dermatitis 1989;20:280-6.

32 Nethercott JR, Lawrence MJ. Allergic contact dermatitis due to nonylphenol ethoxylate (Nonoxynol-6). Contact Dermatitis 1984;10:235-9.

33 Kabasawa Y, Kanzaki T. Allergic contact dermatitis from the surfactant in Hibitane ${ }^{\mathrm{R}}$. Contact Dermatitis 1989;20:378-9.

34 Meding B. Occupational contact dermatitis from nonylphenolpolyglycolether. Contact Dermatitis 1985;13:122-3.

35 Ludwig E, Hausen BM. Sensitivity to isopropyl alcohol. Contact Dermatitis 1977;3:240-4.

36 Frosch PJ, Pekar U, Enzmann H. Contact allergy to propylene glycol. Do we use the appropriate test concentration? Dermatol Clin 1990;8:111-3.

37 Foussereau J, Benezra C, Maibach HI. Occupational contact dermatitis. Clinical and chemical aspects. Copenhagen: Munksgaard, 1982.

38 Børglum B. Survey on the use of cleaning agents in institutions. In: Nielsen J, Bach E. (ed.): Work environment and health among Danish cleaners. Copenhagen: The Danish Working Environment Fund, 1993 (in press)

Accepted 18 January 1993 